\title{
FORMAÇÃO DE EDUCADORES DE TURMAS MULTISSERIADAS: a narrativa como dispositivo formativo
}

\author{
Selma Costa Pena \\ Douglas Almeida de Oliveira
}

\section{Resumo}

Resultado de processo formativo do Programa Escola da Terra, o texto analisa uma prática de formação continuada, com professores/as, coordenadores/as pedagógicos e tutores/as de turmas multisseriadas, do município de Santarém, oeste do estado do Pará. A narrativa como dispositivo formativo foi elemento metodológico de construção de dados, permitindo recuperar e reconstruir os processos formativos dos professores, por vezes silenciados ou pouco considerados nos processos de pesquisas e de formação docente. Os resultados dessa prática formativa apresentam o abandono histórico a que vem sendo submetida a educação do campo no estado do Pará, convergindo para o já demonstrado nas legislações educacionais e na própria concepção de educação do campo. Conclui-se que a formação continuada implementada pelo Programa Escola da Terra apresentou outra forma de ver e de pensar o trabalho docente, a partir de suas narrativas, da discussão realizada com seus pares, das leituras realizadas e das sínteses construídas coletivamente.

Palavras-chave: formação docente; narrativas; turmas multisseriadas; educação do campo.

\section{EDUCATION TEACHERS FOR MIXED GRADE GROUPS:} narrative as an educational tool

\begin{abstract}
The current paper arises from the formative process carried out within the Escola da Terra Program. It analyses the practice of continuous education including teachers, pedagogical coordinators and tutors of mixed grade classes, in Santarém, western of Pará, a northern state in Brazil. Narrative as a formative tool was employed in data construction, which allowed the teachers to retrieve and rebuild their educational processes since they are at times silenced or poorly considered in researches and teacher education programs. The results of this educational practice revealed the historical abandonment rural education in the State of Pará, northern Brazil, has been subjected to which converges towards what is already present in educational legislation and in the conception of rural education itself. The conclusion is that the continuing education carried out within the Escola da Terra Program revealed a different approach to understand teaching work that stems from their narratives and discussions with their peers, as well as their readings on the issue and the syntheses collectively built.
\end{abstract}

Keywords: teacher education; narratives; mixed grade classes; rural education. 


\section{FORMACIÓN DE EDUCADORRES DE AULAS MULTIGRADO: la narrativa como dispositivo de formación}

\section{Resumen}

Resultado del proceso formativo del Programa Escola da Terra, el texto analiza una práctica de formación continua, con profesores, coordinadores pedagógicos y tutores de aulas multigrado, del Municipio de Santarém, al oeste del Estado de Pará. La narrativa como dispositivo formativo fue el elemento metodológico de construcción de datos, permitiendo recuperar y reconstruir los procesos formativos de profesores, a veces silenciados o poco considerados en los procesos de investigación y formación docente. Los resultados de esta práctica formativa muestran el abandono histórico al que ha sido sometida la educación rural en el Estado de Pará, convergiendo con lo ya demostrado en la legislación educativa y en la propia concepción de la educación rural. Se concluye que la educación continua implementada por el Programa Escola da Terra presentó otra forma de ver y de pensar el trabajo docente, a partir de sus narrativas, de las discusiones llevadas a cabo con sus pares, de las lecturas realizadas y de las síntesis construidas colectivamente.

Palabras clave: formación docente; narrativas; aulas multigrado; educación rural.

\section{INTRODUÇÃO}

Como resultado do processo formativo do Programa Escola da Terra, das Águas e da Floresta da Amazônia, este artigo discute uma prática de formação continuada, com professores/as, coordenadores/as pedagógicos e tutores/as das escolas do campo, de turmas multisseriadas, do município de Santarém, no oeste do Estado do Pará. A prática de formação intencionou trazer os sujeitos participantes para o centro dos debates educacionais, conferindo importância e reconhecimento as suas histórias de formação.

$O$ interesse em desenvolver essa prática formativa deveu-se, sobretudo, pelo reconhecimento da carência (e quase ausência) de políticas públicas educacionais voltadas para os educadores de turmas multisseriadas espalhadas pelo Brasil e, em especial, pela região da Amazônia paraense. Esta ausência representa um posicionamento que ignora a realidade nacional, pois no Brasil $70,4 \%$ das escolas do campo são ou têm turmas multisseriadas. Turmas que atendem aproximadamente 1.264 .626 educandos, correspondendo ao total de $21,4 \%$ da matrícula do campo (INEP, 2015). O Pará, em 2015, registrou um total de 3.488 escolas do campo que são multisseriadas, representando um percentual de $42 \%$ das escolas que atendem aos anos iniciais do ensino fundamental (INEP, 2015).

Dentro dessa realidade, temos o município de Santarém, localizado na meso região do baixo Amazonas, com uma enorme quantidade de escolas localizadas no campo e um corpo docente em sua grande maioria composto por profissionais em situação de contrato temporário $85 \%$, segundo a Secretaria de Educação do Município - e com um histórico de formação continuada permeada por cursos aligeirados, distante das problemáticas sociais, culturais, econômicas que constituem o sujeito do campo.

$\mathrm{Na}$ tentativa de se contrapor a esse tipo de prática formativa, com base na articulação entre as perspectivas dos estudos que versam sobre história de vida, narrativas (auto)biográficas e formação docente, desenvolvemos, no período de 2014 a 2015, uma prática formativa que objetivou recuperar e reconstruir, por meio das narrativas de formação escritas por 
professores/as de diferentes turmas multisseriadas seus processos formativos, apreendidos ao longo de suas vidas e, por vezes, silenciados ou pouco considerados nas práticas de formação docente, atentando às dificuldades, avanços, desafios por eles vivenciados em suas práticas cotidianas. Dessa forma, juntamo-nos a outros pesquisadores que investem em abordagens qualitativas (método biográfico, histórias de vida, entre outras) demonstrando que, por meio de depoimentos orais ou escritos, cada professor/a traça seu percurso único e diferente dos outros; que ao falar de seu processo particular de profissionalização, de interação com o grupo social a que pertence ou de suas relações com outros grupos sociais, vai falando de si e das pessoas dos grupos com os quais conviveu.

Tais metodologias reabilitam a dimensão histórica do sujeito, restituindo-lhe o direito de contar as histórias de sua vida cotidiana e, portanto, “[...] tornam possíveis que o autor da formação seja também o autor de um discurso sobre a sua formação, tendo acesso, pela sua palavra, ao sentido que dá a essa formação e, mais ainda, a si próprio” (CHENÈ, 1988, p. 90). Esses motivos justificam os estudos sobre pesquisas que consideram a abordagem autobiográfica como mais uma matriz de pensamento, e, por conseguinte, a opção metodológica pela narrativa como elemento formativo e como procedimento de construção de dados.

Dessa forma, se uma primeira relevância desse estudo encontra-se no fortalecimento de um campo de estudos que situa o professor numa perspectiva sócio-histórica - como um sujeito que aprende a partir de incursões em seus processos de aprendizagem, narrando sobre tais percursos -, outra relevância significativa está em contribuir para a construção de um conhecimento de áreas disciplinares que relacione histórias de vida, narrativa docente e práticas educativas, atentando às possíveis implicações que possam advir para o campo de estudos de formação dos professores da educação do campo.

Assim, organizamos este artigo desenvolvendo, inicialmente, uma breve apresentação do Programa Escola da Terra, como programa de formação de professores da educação do campo. A seguir, caracterizamos o Programa Escola da Terra, das Águas e da Floresta da Amazônia, ocorrido na cidade Santarém/Pará. E, por fim, apresentamos alguns dos resultados do processo formativo, trazendo uma discussão teórica acerca do lugar das narrativas memorialísticas e o lugar da escrita na formação de educadores. Finalmente, algumas conclusões relativas à importância de um trabalho dessa natureza no processo formativo de educadores do campo.

\section{PROGRAMA ESCOLA DA TERRA: FORMAÇÃO CONTINUADA DE PROFESSORES EM SERVIÇO NAS ESCOLAS DO CAMPO}

O programa Escola da Terra é uma das ações do Programa Nacional de Educação do Campo (PRONACAMPO), lançado pelo Governo Federal por meio de Portaria n. 86, que define ações específicas de apoio à efetivação do direito à educação dos povos do campo e quilombolas, considerando as reivindicações históricas dessas populações. O programa tinha por objetivo promover a melhoria das condições de acesso, permanência e aprendizagem dos estudantes do campo e quilombolas em suas comunidades, por meio do apoio à formação permanente de professores que atuam nas turmas dos anos iniciais do ensino fundamental compostas por estudantes de variadas idades (turmas multisseriadas), bem como oferecer recursos didáticos e pedagógicos a essas escolas.

Cada docente faria o curso no município de sua localidade, sob a forma de alternância, que significa um período de frequência presencial nas universidades, denominado tempouniversidade, e outro de ações realizadas em seus locais de trabalho, chamado tempo- 
comunidade, isso tudo sob acompanhamento de um/a tutor/a, indicado por cada secretaria de educação dos municípios. Mediante adesão, todas as atividades formativas foram realizadas por instituições de ensino superior públicas. Em 2013, sete universidades federais iniciaram um projeto-piloto do Programa Escola da Terra: Universidade Federal da Bahia (UFBA), do Pará (UFPA), do Amazonas (UFAM), de Pernambuco (UFPE), de Minas Gerais (UFMG), do Rio Grande do Sul (UFRGS), e do Maranhão (UFMA).

No estado do Pará, o programa encontrou terreno fértil para se desenvolver, pois à época estimávamos um grande número de docentes que atuavam nas escolas do campo e quilombolas, espalhados pelos 144 municípios, com poucas formas de processos de formação continuada e com uma avaliação extremamente negativa do antigo programa de formação do governo Federal, o Escola Ativa. O perfil desses docentes era de profissionais que residiam em lugares muito distantes ou de difícil locomoção para os centros das cidades, onde poderiam cursar o ensino superior ou algum tipo de curso de formação continuada.

Pela peculiaridade que nos cerca no Pará, o programa foi chamado de "Programa Escola da Terra, das Águas e da Floresta da Amazônia". Foi desenvolvido pela Universidade Federal do Pará (UFPA), em parceria com a secretaria de educação e com nove municípios, quais sejam: Cametá, Acará, Abaetetuba e Moju, Bragança, Augusto Correa, Tracuateua, Santarém e Mojui dos Campos. Juntos, perfaziam um total de 1.323 educadores de turmas multisseriadas do campo e quilombola participando do processo de formação continuada.

O programa teve sua organização curricular inspirada na perspectiva da Pedagogia da Alternância, tendo como eixo central a Organização Interdisciplinar do Trabalho Pedagógico nas Escolas do Campo e Quilombolas da Amazônia, e como subeixos: 1) A identidade da escola do campo e quilombola - transgressão do paradigma (multi) seriado de ensino e 2) Interdisciplinaridade na organização do trabalho docente: planejamento, currículo, metodologias e avaliação nas escolas do campo e quilombolas.

Essa foi a forma encontrada para buscar a ruptura com o saber estritamente disciplinar e pautar a ação pedagógica por meio da integração entre os saberes das diferentes áreas do conhecimento. A intenção era a de não mais entender a disciplina em seu aspecto isolado, mas a partir da integração/interação entre as diferentes disciplinas com vistas a promover a composição do conhecimento a partir de uma área mais ampla. Isso implicou, por exemplo, em não mais visualizar a matemática e/ou a disciplina ciências em seus aspectos fragmentados, mas, sobretudo, a partir do diálogo entre estas áreas curriculares, desenvolver as bases epistemológicas que construíssem o entendimento de formação integral das dimensões da aprendizagem.

Tal entendimento significa para Hage (2014) transgredir a concepção seriada de construção do conhecimento e, para isso, é necessário que a escola incorpore em suas práticas pedagógicas o acúmulo de experiências dos sujeitos participantes. Sujeitos esses que resistem e que procuram realizar práticas diferenciadas mesmo em condições adversas e de limitações profundas. Assim, a articulação entre a vida, o trabalho e as culturas do campo, com os processos educativos, o diálogo entre os conteúdos acadêmicos e os saberes adquiridos nas práticas produtivas e culturais dos sujeitos do campo foram princípios fundamentais para que as escolas multisseriadas conseguissem transpor as barreiras estruturais que vivenciavam no seu cotidiano.

A escola multisseriada, enquanto território, está marcada e reconhecida como espaço de conflito, de contradições, de diversidade, de tradições e de costumes que são apreendidos na convivência com os sujeitos. Seu contexto se apresenta como um paradoxo: de um lado, temos um espaço muito precarizado e esquecido pelas políticas educacionais. Um espaço no qual, ao professor, são atribuídas múltiplas responsabilidades: ensinar, higienizar o ambiente, fazer 
trabalho de secretaria e de cozinheira. Ao lado disso tudo, temos as diferentes possibilidades de trabalho docente construídas pelos educadores que "[...] constroem situações criativas e inovadoras de ensino desafiando as condições adversas que configuram a realidade existencial dessas escolas" (HAGE, 2014, p. 2).

Considerando esse contexto contraditório e adverso, decidimos trabalhar em todos os módulos iniciais de formação com as vozes dos sujeitos que cotidianamente constroem as escolas do campo. Nossa ideia era a de construir dados de análises relevantes e pertinentes à área de educação, que colaborassem tanto para o debate sobre organização do trabalho e formação docente, quanto para a prática pedagógica de professores das turmas multisseriadas.

Para nós, a experiência de vida dos/as professores/as tinha um caráter educativo, pois destacava o modo como a práxis pedagógica e a constituição da identidade docente poderiam ser influenciadas pelas experiências pessoais e pelas situações vividas em suas atuações profissionais. Além disso, essa atividade permitia ainda o levantamento e debate sobre informações relacionadas às condições de trabalho nas escolas do campo e as formas de interação dos educadores com as comunidades em que atuavam.

\section{O PROGRAMA ESCOLA DA TERRA, DAS ÁGUAS E DAS FLORESTAS EM SANTARÉM}

A cidade de Santarém teve sua fundação datada em 22 de junho de 1661. Localizada na meso região do Baixo Amazonas, é carinhosamente conhecida como a "Pérola do Tapajós". Destacando-se por suas belezas naturais, Santarém distancia-se da capital do estado por aproximadamente $800 \mathrm{~km}$, sendo sua terceira cidade de referência, com uma população de 294.447 mil habitantes (IBGE, 2016).

No campo educacional, a Pérola do Tapajós atende a educação básica, profissionalizante e o ensino superior. Possui 445 escolas, distribuídas na rede estadual e municipal. Na rede estadual, das 35 escolas, somente uma localiza-se no campo; já na rede municipal, das 410 escolas, 321 estão na zona rural, assim distribuídas: 233 estão na região dos rios e várzeas e $88 \mathrm{em}$ área de planalto (SANTARÉM, 2016, p. 8) ${ }^{1}$. Das 100 escolas participantes do programa, 50\% estavam em situações diferenciadas, $19 \%$ eram escolas localizadas em assentamento, $18 \%$ estavam em áreas de várzea, 7\% eram escolas indígenas e 6\%, quilombolas.

\section{A EXPERIÊNCIA FORMATIVA: A NARRATIVA COMO DISPOSITIVO FORMATIVO}

No município de Santarém, o programa Escola da Terra se desenvolveu no período de abril de 2014 a agosto de 2015, com carga horária de 200 horas organizadas em períodos formativos denominados Alternância Pedagógica: tempo universidade (160h) e tempo comunidade (40h), tempos formativos muito importantes para o entendimento dialógico da relação teoria e prática.

Nossa intenção era a de desenvolver com os professores um processo formativo apoiado em uma abordagem que compreende a subjetividade como modo de produção de conhecimentos

${ }^{1} \mathrm{O}$ Rio e o Planalto são compreendidos como espaços sociais que trazem especificidades próprias, o que faz com que a Secretaria mude sua forma de estruturação, passando da clássica organização por níveis de ensino para uma organização centrada nos territórios (LEITE, 2012, p. 01). 
(JOSSO, 2004), envolvendo-os ativamente no processo de apropriação do conhecimento. Precisávamos de uma porta de entrada para abordar o fazer docente, em que os professores pudessem aprender sobre sua profissão na partilha com os colegas, nas conversas com os formadores, com os alunos, nos momentos de estudos e avaliações. Para isso, optamos pelas narrativas escritas desses docentes, como um dispositivo formativo. Nosso primeiro eixo formativo teve como tema "Todas as vozes escrevendo um presente/futuro melhor para a educação do campo".

Nosso interesse pela narrativa autobiográfica justifica-se por tratar-se de uma abordagem que "[...] valoriza o indivíduo e busca apreender os processos de formação no contexto de histórias pessoais" (DOMINICÉ, 2000, p. 39). Assim, pressupõe-se que a narrativa autobiográfica, "[...] realizada no seio do grupo de adultos e sistematizada, posteriormente, por escrito, beneficiaria o narrador, no sentido em que o exercício de análise e interpretação dos fatos modificaria suas representações e a forma como elas incidem sobre sua vida" (PASSEGGI, 2003, p. 01).

Essa não foi uma proposta fácil de discutir com os professores, que demonstravam em suas poucas falas que o processo de formação que conheciam não priorizavam momentos de análise e de crítica da realidade social, política, econômica e cultural - e muito menos que isso pudesse se materializar por meio de seus dizeres. Os/as professores/as visivelmente não viam possibilidades numa concepção de formação de professores que assumisse como pressuposto epistemológico escutar as vozes dos sujeitos participantes e considerar seus processos de escrita como formas de conhecer os processos formativos, apreendidos ao longo de suas vidas, trazendo à discussão a realidade da profissão, seu cotidiano e sua experiência.

A discussão oral quebrou o silêncio já bem conhecido nos encontros formativos. Deparamo-nos nos primeiros dias de formação com um/a professor/a apático/a, descrente, profundamente silencioso/a, marcado/a por sinais de culpa pelos processos de fracasso das práticas escolares. Um/a professor/a que via o fracasso escolar sendo enfrentado no município por meio de inúmeros projetos de formação, a exemplo do Pacto Nacional pela Alfabetização na Idade Certa (PNAIC), criado pelo MEC em 2012 e do qual participavam ativamente. Nada os fazia sair de suas zonas de conforto. Por isso, nossa tarefa primeira foi a de tentar tirá-los dessa inércia, que não lhes deixavam à vontade para explanar e defender suas posições.

Essas discussões iniciais foram também fundamentais para estabelecermos uma relação inicial de confiança e, de outra forma, apresentar a eles possibilidades de processos formativos construídos colaborativamente, já que um dos objetivos desse módulo inicial era o de conhecer o professor do campo e suas posições, a fim de criar um plano de formação que atendesse também aos seus interesses. Além disso, essa opção metodológica pelas narrativas, de certa forma, nos fazia ir na contramão de abordar o fazer docente somente considerando seu plano de trabalho mais pragmático, suas agendas de tarefas ou algumas observações pontuais de suas práticas escolares. As narrativas poderiam nos colocar diante das práticas sociais dos professores, como bem afirma Andrade (2014):

Pode-se conceber passar do plano das interações entre atores para o das práticas sociais dos professores, se inscrevermos tais atividades em um plano menos individual, tomando os gestos, o seu desempenho, como inscritos em formas institucionais de lidar com as situações. [...] Ainda se pode ampliar o zoom, enquadrando estes dois planos de compreensão para a ação docente como condição para que as produções discursivas dos professores sejam atos (p. 8). 
Imbuídos dessa ideia, defendíamos também que a formação ia além do processo de atualização do professor no campo de apreensão de técnicas de ensino; que precisamos de uma formação que fundamentalmente o prepare para uma compreensão de si, de seu papel profissional, da situação escolar como um todo, encontrando meios de interpretar melhor a realidade em que vive e ampliando seu discernimento acerca dos pressupostos filosóficos, sociais e políticos que envolvem a educação e, consequentemente, sua formação docente. Dessa forma, defendemos uma concepção de formação na perspectiva proposta por Nóvoa (1992), ao destacar que a formação não se constrói somente por acumulação (de cursos, de conhecimentos ou de técnicas), mas também por meio de trabalho de reflexividade crítica sobre as práticas e de (re) construção permanente de uma identidade pessoal.

A partir dessas indicações com o processo de discussão oral, iniciamos a construção dos cadernos de memórias com os/as professores/as. Cada professor/a produziu o seu caderno, a partir das indicações já discutidas anteriormente. Importante considerar que esse primeiro módulo teve a duração de três dias e que a elaboração da narrativa escrita deu-se somente no segundo dia quando os/as professores/as já haviam compreendido melhor a importância dessa estratégia formativa, mas, ainda assim, para que ficassem mais à vontade solicitamos que a escrita inicial fosse mais livre, o que lhes levou a intitular seus cadernos sob os nomes de "Caderno de lembranças", "Histórias de vida", "Minha vida de professor da educação do campo", etc. Ao longo dos três dias, eles foram aprofundando suas escritas tomando como parâmetro os eixos formativos do programa discutidos no primeiro dia de formação.

Após terem escrito suas narrativas, os/as professores/as se organizaram em pequenos grupos de estudo e trabalho, em que socializaram suas memórias, buscando ecos entre as histórias; como resultado elaboraram socializações para o "grupão". Seguida da apresentação dos grupos, em cada turma, os formadores responsáveis realizaram sínteses das discussões, cruzando informações contidas nos textos, com os de autores/as que pesquisavam questões semelhantes a fim de chegar a conclusões coletivas acerca de determinado assunto. As principais questões destacadas para essa discussão foram a caracterização das escolas públicas do campo e quilombola e sua precarização, valorização dos/as professores/as (temporários e sem formação), processos de formação continuada de professores/as.

A partir disso, nas etapas seguintes discutimos um grande tema intitulado Da situação de precariedade às pautas históricas de luta por uma educação básica do campo; conceituação e princípios pedagógicos da educação do campo e os elementos centrais da LDB 9394/96 que tratam de questões sobre curriculo diferenciado para educação nas escolas rurais, assim como elementos das Diretriz̨es Operacionais da Educaşão do Campo. Essa foi nossa (formadores/as e professores/as) grande síntese. Foi um momento muito importante, que nos possibilitou desnaturalizar e nomear algumas situações apresentadas nas narrativas e que nos deu condições de planejar todas as etapas das $200 \mathrm{~h}$ de curso de aperfeiçoamento.

Agrupamos para análise nesse artigo o início do trabalho com as narrativas referentes a: i) perfil do educador do campo; ii) a cartografia das escolas multisseriadas, iii) desenvolvimento profissional. 


\section{O/A PROFESSOR/A DE EDUCAÇÃO DO CAMPO, A CARTOGRAFIA DAS ESCOLAS MULTISSERIADAS E O DESENVOLVIMENTO PROFISSIONAL DOS/AS PROFESSORES/AS}

Dos/as professores/as que participaram da formação em Santarém, 135 professores/as (71\%) eram temporários e 54 professores/as (29\%) efetivos. No que se refere à escolaridade, 126 tinham cursos de graduação, 28 professores/as cursavam a segunda graduação, 27 cursavam a primeira graduação por meio do Plano de Ações Articuladas de Formação de Professores da Educação Básica (PARFOR) e oito professores/as possuíam apenas magistério, sem graduação.

A maioria tinha origem em famílias oriundas do campo, de baixa renda, escolarização realizada com dificuldades e muito esforço; alguns foram "empurrados para a função de professor" por conta da falta de oportunidades profissionais e condição econômica; uns residiam próximo às escolas do campo, outros que moravam distante, possuíam dificuldades de transporte, enfrentavam situações adversas para trabalhar nas escolas. A grande maioria acumulava tarefas burocráticas além da docência, se preocupava com renda para assegurar melhorias de vida e trabalho, se esforçava para adquirir equipamentos e estudar; alguns trabalhavam em mais de uma escola em comunidades diferentes; a maioria deles se encontrava em condições precárias de profissionalização, sem estabilidade, baixos salários, pagamentos com atraso e sem direitos a $13^{\circ}$ salário; reconheciam as dificuldades dos alunos quanto à realidade socioeconômica, com diferentes condições de aprendizagem; enfrentavam a dificuldade de trabalhar com multissérie e compreendiam a necessidade de buscar a excelência na sua ação docente para não comprometer a qualidade do processo ensino-aprendizagem por conta de tal realidade. Sobre essas questões, assim se manifestaram:

Sou filha de camponês e de família simples. Sou formada em Licenciatura em Pedagogia pelo Parfor. Antes de ser professora sempre acompanhei minha família nas tarefas da terra. [...] estudei muito tempo nas escolas daqui mesmo, mas queria fazer o magistério e aí tive que sair de minha comunidade, ir para longe de minha família e às vezes tendo que morar na casa dos outros. (Marcia). ${ }^{2}$

As narrativas nos fizeram refletir também sobre o papel social desempenhado pelo/a professor/a, que envolve considerar todo o contexto em que ele/a foi formado/a, dentro e fora da escola e com isso os conceitos dos quais se apropriou ao longo de sua trajetória de vida e das formas como se reconhece professor/a:

Comecei a trabalhar como professora após um acidente que aconteceu com a minha mãe no caminho do trabalho, foi quando fui ser sua substituta indicada pelo seu gestor. Nesse tempo eu ainda não tinha formação. Meu ensino médio foi em ciências humanas, mas como no momento não tinha quem ficasse $o$ lugar dela eu fiquei assim mesmo. A turma era bisseriada com 13 alunos na comunidade Santa Rosa, próximo a comunidade onde moro. Quem conseguiu para mim esse emprego foi um vereador da cidade. Com meu desempenho o

${ }^{2}$ Os nomes dos professores são fictícios. 
gestor me incentivou a fazer faculdade e assim fiz. Então eu me formei professora em vários lugares (Joana).

A partir dessa narrativa, percebemos o quanto a formação passou a ser concebida como um processo multifacetado, contínuo e inter-relacional, desencadeado no percurso das experiências familiares, escolares, sociais e profissionais de cada professor. Dito de outra forma: significou considerar que a formação não perpassa exclusivamente pelos cursos acadêmicos, mas em outros diversos contextos, sofrendo influências de diversos sujeitos e diversas referências que vão dando sentidos singulares às dimensões pessoais e profissionais dos professores, o que de certa forma desloca o foco de análise de uma formação marcada exclusivamente pelos saberes científicos, técnicos, operacionais ou aplicados para (também) as discussões dos saberes e práticas docentes, explicitando os sentidos das experiências nas aprendizagens dos sujeitos.

Acreditamos que tal tendência ou paradigma tenha melhores chances de dar conta de questões mais complexas dos processos de aprendizagem que recobrem a formação dos profissionais da educação porque os processos de formação são produzidos historicamente. Quando a professora Joana narra "[...] Comecei a trabalhar como professora após um acidente que aconteceu com a minha mãe no caminho do trabalho", evidencia características da docência como uma profissão que lida com sujeitos e situações inusitadas e imprevisíveis, que podem gerar incertezas, tristezas, alegrias, conflitos de valores e dúvidas.

Desta forma, não podemos limitar a prática pedagógica dos docentes a um mero repasse de informações e conteúdos que acumularam durante seus cursos de formação inicial. Na escola, como mostrarão os fragmentos das narrativas aqui apresentadas, o professor assume responsabilidades bem maiores, tendo em vista a complexidade que se estabelece em torno do ato de ensinar.

A política de formação para os/as educadores/as do campo, as condições de trabalho, também tiveram lugar de destaque nas narrativas:

\begin{abstract}
Nossa formação aqui é muito precária. Temos que nos deslocar para o centro de Santarém e isso é muito ruim; alguns de nós quando consegue chegar aqui tem que ficar hospedado dentro de barcos, sem condições de vida digna. Eu fico me perguntando: por que tudo pra gente tem que ser tão sofrido? A gente vem pra formação e fica super ancioso para pegar o máximo possível de atividades, de sugestões para fazer com as crianças. Eu queria que tivesse um livro didático para ver se as coisas melhoravam (Lúcia).
\end{abstract}

Essa ausência de uma politica específica para os educadores da educação do campo é apontada por Arroyo (2007), quando diz que essa falta "[...] tem por base a ausência de uma política pública específica de educação ou o não reconhecimento do direito à educação básica da infância, adolescência e juventude do campo" (p. 170). Ora, se o sujeito do campo tem apenas que saber minimamente mexer na terra para alimentar esse país, do que lhe valeria um diploma nas mãos? Ao que parece, a lógica era: acaba-se com o rural, tendo como consequência acabar junto com quaisquer dos problemas que daí viesse.

Vimos acima que $71 \% \mathrm{dos} /$ as professores/as eram temporários e somente $29 \%$, efetivos, ocasionando grande rotatividade de professores/as nas escolas. Entre os efetivos, isso ocorria porque, ao se deparar com as condições materiais das escolas, solicitavam transferências. E os contratados estavam sempre se renovando por conta de novos contratos a cada ano. Sobre isso Andrade e Di Pierro (s. d.) afirmam: 
DOI: $10.12957 /$ teias. $\%$ Y.50910

É raro que os professores habilitados, a maioria dos quais vivem nos centros urbanos, tenham as escolas rurais como primeira opção de trabalho, o que faz com que a docência nas escolas do campo seja atribuída a professores em início de carreira que, à primeira oportunidade, solicitam transferência para escolas urbanas. A distância das escolas e a sobrecarga de trabalho nas escolas rurais (às quais falta pessoal de apoio e onde predominam as classes multisseriadas) torna ainda menos atraentes os baixos salários pagos aos professores (ANDRADE; DI PIERRO, s. d., p. 7-8).

Dos/as professores/as que atuavam nas escolas, eram poucos os que permaneciam por muito tempo nas comunidades, e a consequência disso era a pouca compreensão das particularidades que compõem a identidade das crianças com as quais conviviam. Vemos isso muito bem retratado na narrativa abaixo:

Às vezes eu não entendo o que acontece com as crianças. Ensino horas sobre como falar corretamente algumas palavras ou como falar algumas palavras e não outras e eles continuam falando essas coisas estranhas. Teve uma vez que uma criança me disse que sua avó tinha dito pra ele que a fala que se fala na escola não era a mesma que se falava em casa (Maria).

Sem querer desconsiderar o conhecimento da norma culta construído historicamente e também necessário de ser apreendido, essa é ainda uma experiência que mostra um único modelo de currículo, tomando como referência o centro urbano, sem considerar os processos de discriminação que os sujeitos sofrem por meio da linguagem. Nas turmas multisseriadas, em sua grande maioria, os professores trabalham com os livros didáticos como a única fonte para a seleção e organização dos conhecimentos, sem atentar para as implicações curriculares resultantes dessa atitude, uma vez que esses manuais pedagógicos impõem a definição de um currículo deslocado da realidade, da vida e da cultura das populações do campo.

No exemplo da narrativa acima, a avó da criança sinaliza muito bem para isso, quando sente a diferença da linguagem utilizada na escola e na comunidade, como se o que se fala na escola fosse então uma segunda língua e não nossa língua materna. Há, portanto, um estranhamento para a avó, mas uma naturalização desse currículo urbanocêntrico por parte da professora: a cidade e sua linguagem mostrada nos livros didáticos é o lugar do progresso, da civilidade, da verdade absoluta. Por meio dessas narrativas foi possível problematizar alguns processos cristalizados: o que ocorre quando o Estado opta por uma variação da língua para ser oficial; como se efetiva esse controle social. Desnaturalizar situações como essas a partir das narrativas foi além de um momento formativo para o professor, um espaço auto formativo para nós formadores.

Ao discorrer sobre as maiores dificuldades enfrentadas no decorrer de suas atuações em sala de aula, os professores revelam, de certa forma, o "retrato" das escolas situadas no campo:

A escola de multissérie é para mim um local de total abandono pelo poder público. Não possuem prédio próprio; trabalhamos quase sempre em lugares emprestados pela comunidade ou pela igreja: única sala, com quadro de giz, às vezes sem energia, com aluno da educação infantil ao quinto ano, que eu preciso dividir o quadro em quatro partes para que cada um aprenda de acordo com sua série. São escolas precárias, mas se os alunos não tiverem essas escolas onde irão estudar? Aqui as distâncias são outras: nossas crianças ou caminham longas distâncias ou chegam aqui pelos barcos (Joana). 
Em suas narrativas, os/as professores/as mostram o quanto, mesmo precarizada, a escola do campo ainda é o único lugar para que as crianças estudem, infelizmente. Uma escola que, por suas condições de quase total expropriação, concorre para o fracasso da criança e da escola pública.

Ainda que de forma breve, os/as professores/as revelam uma verdade: as escolas do campo, em especial as multisseriadas, encontram-se localizadas nas pequenas comunidades rurais, muito afastadas das sedes dos municípios, onde a população a ser atendida na escola não atinge o contingente definido pelas secretarias de educação para formar uma turma por série. Por terem essas características, aparecem como a "salvação da pátria" e sua precariedade passa a ser naturalizada pelo discurso de "ruim com elas, pior sem elas", "são escolas precárias, mas se os alunos não tiverem essas escolas onde irão estudar?". Narrativas como essas nos possibilitaram a discussão acerca da identidade das escolas públicas do campo e quilombola; da precarização das escolas e da construção coletiva de uma proposta pedagógica.

Ao concluir esse item de discussão, não poderíamos deixar de assinalar o que mais nos chamou atenção nos dizeres dos professores: o escasso investimento nas condições de infraestrutura das escolas do campo; o pouco investimento pedagógico, quando presenciamos escolas sem material pedagógico, sem assessoria pedagógica mais atuante e com livros didáticos alheios à realidade dos alunos do campo. A naturalização e, de certa forma, aceitação dos/as professores/as a essas situações tão adversas (no início de suas narrativas), tanto das condições materiais em que se encontram as escolas quanto das condições pedagógicas, foi um alerta para nós formadores de que isso precisaria de mediação, fosse com nossas proposições ou a partir das diferentes formas de estudos (leituras dos textos, vídeos, etc).

Os/as professores/as que tinham o curso superior possuíam diferentes licenciaturas: Letras, Pedagogia, Geografia, Matemática, Ciência Biológicas, etc, mas todos atuavam nos anos iniciais. Raramente, esses/as professores/as atuavam do sexto ao nono ano ou no ensino médio, o que, de certa forma, gerava grande insatisfação profissional. A questão é que todas essas licenciaturas realizam formação de forma generalista, concebendo a escola como uma só, sem pensar em práticas contextualizadas e muito menos em espaços e lugares diferentes, o que vem na contramão do almejado para o educador do campo que tem uma realidade que "[...] exige um educador que tenha compromisso, condições teóricas e técnicas para desconstruir as práticas e ideias que forjaram o meio e a escola rural" (ANTUNES-ROCHA, 2010, p. 395). Nessa mesma linha, Arroyo (2007) pondera que:

Em nome de formar um profissional único de educação, um sistema único, com currículos e materiais únicos, orientados por políticas únicas, os direitos dos coletivos nas suas diferenças continuam não garantidos. Os piores índices de escolarização continuam nos "outros", nos coletivos do campo, indígenas, pobres trabalhadores, negros. Essa perversa realidade, tão constante quanto excludente, interroga a tradição de políticas e normas generalistas, pretensamente universalistas (p. 62).

As discussões advindas das narrativas dos/as professores/as apresentam muito bem esse processo formativo realizado no ensino superior e depois nas formações continuadas:

Eu fiz o curso de Pedagogia. Não tenho lembranças de ter feito uma discussão sequer sobre as escolas e as crianças que estudam no campo. É como se fosse uma coisa só: cidade e campo, como se vivêssemos os mesmos problemas. Não somos professores que moram nas cidades grandes, muitos de nós mora 
próximo dos rios, das vicinais, das pequenas vilas, mas isso sempre pareceu invisível (Dea).

Confesso que estou cheia disso tudo. Sempre as mesmas histórias: fracasso das crianças, escolas em péssimas condições, sem material pedagógico, salário baixo etc etc. Os cursos de formação continuada deveriam parar de dizer que se as coisas estão ruins, que a culpa só é nossa que não sabemos dar aulas. Tudo bem que temos culpa nisso, mas não é só nossa (Joana).

Esses e outros trechos semelhantes foram alvo de discussão no grupo de professores/as, que declararam nunca ter parado para pensar sobre isso porque os cursos de formação eram vistos mais como premiações, para os que conseguiam fazer, do que como direito de cada professor. Ao serem perguntados sobre como gostariam que fossem os cursos, divergiram nas sugestões: alguns reafirmavam que gostariam de cursos que tratassem de metodologias prontas e assertivas, que ensinassem a fazer plano, a exemplo do Programa/Pacto Nacional de Alfabetização na Idade Certa (PNAIC); outros defendiam cursos presenciais, em suas localidades de trabalho, cursos que não fossem aligeirados e nem aos finais de semana. Muitos defenderam a ideia de que os espaços formativos devem constituir-se em espaços que favoreçam a articulação entre desenvolvimento profissional e trajetória biográfica.

Ao que parece, para esse segundo grupo de professores, a formação se daria no entrecruzamento entre abordagens que preconizam práticas reflexivas e o uso de (auto) biografias, o que não significaria apontá-los como formas modelizadoras de formação nem tampouco afastá-los das discussões mais amplas acerca da categoria docente (a categoria trabalho, por exemplo), da construção do coletivo de classe. Para nós formadores, a cada encontro, a cada discussão e leitura das narrativas, ficava perceptível que a prática docente não se construía eminentemente quando os/as professores/as entravam em contato com as teorias pedagógicas, “[...] mas encontrava-se enraizada em contextos e histórias individuais, que antecedem, até mesmo, a entrada deles na escola, estendendo-se por todo o percurso da vida escolar e profissional" (CATANI, 1997 p. 34). Talvez por esse motivo tenham declarado que gostaram da ideia de serem ouvidos, de puderem opinar, discutir, divergir, sugerir sobre os rumos de sua formação.

Isso para dizer que os trabalhos de formação que consideram a experiência do/a professor/a, sua história e suas representações não sobrepujam o sujeito em detrimento do coletivo, mas a exemplo do que ocorreu nesse processo formativo em Santarém, ao evidenciar o sujeito e sua condição historicamente construída, evocam a condição de seus pares e, consequentemente, de sua classe. Quantas outras vozes vieram juntas às dos professores/as no decorrer dessa formação! Pai, mãe, avós, vizinho, professor da escola básica, professor/a do ensino superior, autores/as de livros..., enfim, quantas vozes disseram coisas e trouxeram suas representações de tantos outros lugares.

Nesse sentido, as narrativas autobiográficas podem contribuir para os estudos acerca da profissão docente por levar em conta a dimensão das significações pessoais das experiências de trabalho, favorecendo interpretações que contemplam perspectivas dos diversos sujeitos sociais, a partir dos lugares sociais que eles próprios ocupam. Aliado a isso, complementamos dizendo que, nesse processo de narrar suas experiências, de revelar suas percepções, os/as professores/as da educação do campo acenaram para um ato político, fazendo emergir junto à história oficial uma memória muitas vezes silenciada e esquecida, o que pode ser considerado uma conquista de toda categoria profissional. Afinal, quando nós educadores tornamos públicos nossos textos, sejam 
eles orais ou escritos, todos ganham, porque construímos espaços discursivos peculiares e autônomos.

\section{CONSIDERAÇÕES FINAIS}

Os resultados dessa prática formativa apresentam o abandono histórico a que vem sendo submetida a educação do campo no estado do Pará, em especial a formação de seus/suas educadores/as, convergindo para o já demonstrado nas legislações educacionais e na própria concepção de educação do campo. No contexto paraense, os processos formativos, pelo que vimos, ainda está aquém do atendimento à diversidade dos/as professores/as que atuam no campo.

Nesse sentido, trabalhar com as narrativas foi um dispositivo formativo importante que possibilitou aos professores/as apontarem como as políticas de formação docente se efetivam em regiões como a Amazônia paraense, diferenciada por sua heterogeneidade biossociocultural. Dessa forma, a experiência de formação continuada implementada pelo Programa Escola da Terra, na cidade de Santarém/Pará, pode ser indicativo para futuras práticas formativas, em que a vOz docente tenha autoria, materializada nos textos escritos pelos/as professores/as e na discussão sobre o que essas escritas demandam para a educação do campo.

\section{REFERÊNCIAS}

ANDRADE, Ludmila Thomé de. Entre fazer e dizer: atividade docente e práticas pedagógicas escolares, nos atos de escrita na formação raído. Revista do Programa de Pós-graduação em Letras da UFGD / Universidade Federal da Grande Dourados, v. 8, n. 16, jul/ dez. 2014.

ANDRADE, Maria Regina; DI PIERRO, Maria Clara. O Programa Nacional de Educação na Reforma Agrária em Perspectiva: dados básicos para uma avaliação. s. d.

ANTUNES-ROCHA, Maria Isabel. Desafios e Perspectivas na Formação de Educadores: reflexões a partir do curso de licenciatura em Educação do campo desenvolvido na FAE/UFMG. In: SOARES, Lucíola (et al.). Convergências e tensões no campo da formação e trabalho docente. Belo Horizonte: Autêntica, 2010.

ARROYO, Miguel Gonzales. Políticas de formação de educadores do campo. Cad. Cedes, Campinas, v. 27, n. 72, p. 157-176, maio/ago. 2007.

BRASIL. Ministério da Educação. Instituto Nacional de Estudos e Pesquisas Educacionais Anísio Teixeira. Panorama da Educação do Campo. Brasília: MEC/INEP,2015.

BRASIL. Portaria n. 579 de 02 de julho de 2013. Que institui a Escola da Terra. Disponível em pronacampo.mec.gov.br/imagens/pdf/manual escola terra.pdf. Acessado em 21 abr. 2020.

BRASIL. Ministério da Educação. Pacto Nacional Pela Alfabetizạãa na Idade Certa. Brasília: DF, 2012.

BRASIL. Lei de Diretrizes e Bases da Educação 9394/96. Disponível em http://www.planalto.gov.br/ccivil_03/leis/L9394.htm. Acesso em 15 abr. 2020.

CHENÉ, Adele. Narrativa de formação e formação de professores. In: NÓVOA, Antonio; FINGER, Mathias (Org.). O método auto(biográfico) e a formação. Lisboa: Ministério da saúde, 1988.

CATANI, Denice Barbara. et al. História e autobiografia na pesquisa educacional e na formação. In: CATANI, Denice Barbara. Docência, memória e gênero: estudos sobre formação. São Paulo: Escrituras Editora, 1997.

DOMINICÉ, Pierre. Histoire de vie comme processus de formation. Paris: L'Harmatan, 2000. 
JOSSO, Marie-Christine. Experiência de vida e formação. São Paulo: Cortez, 2004.

PASSEGGI, Maria da Conceição. Narrativa autobiográfica: uma prática reflexiva na formação docente. Trabalho publicado nos Anais do II Colóquio Nacional da AFIRSE - UNB - set./2003. Portaria Ministerial n. 579/02/07 PROGRAMA ESCOLA DA TERRA, 2014. SANTARÉM-PARÁ, Secretaria Municipal de Educação. Relatório SEMED/2016. Dez. 2016.

Submetido em maio de 2020 Aprovado em setembro de 2020

\section{Informações dos autores}

Selma Costa Pena

Universidade Federal do Pará

E-mail: selmacpena@gmail.com

ORCID: http://orcid.org/0000-0001-9795-0958

Link Lattes: http://lattes.cnpq.br/2595133066254500

Douglas Almeida de Oliveira

Universidade Federal do Pará

E-mail: biadouglas41@gmail.com

ORCID: https://orcid.org/0000-0002-7237-9246

Link lattes: http://lattes.cnpq.br/9641815061356874 